\title{
Two-sided Absorptive Capacity: Customer Integration in Data-driven Environments
}

\author{
Diana Chernetska \\ Faculty of Business Studies \& Economics, University of Bremen, Germany
}

Copyright $(\mathrm{C} 2017$ by authors, all rights reserved. Authors agree that this article remains permanently open access under the terms of the Creative Commons Attribution License 4.0 International License

\begin{abstract}
Companies are more and more turning to proactive customer integration and look for efficient ways of customer knowledge management. In case of online interaction, companies generate Big Data which holds the potential for the companies in terms of customer knowledge input. The potential of such data can be unfolded using advanced (predictive) analytics technologies. In order to ensure efficient customer integration in such settings, companies should be able to develop absorptive capacity. We assume that the nature of absorptive capacity in data-driven environments could be challenged, considering the intersection of business and technology perspectives. This study sets a foundation of understanding the peculiarities of absorptive capacity in data-driven environments by applying a qualitative case study approach. The study considers perspectives of both, service companies and analytics providers to avoid one-sided biases. The main result is an integration of empirical findings, their analysis against existing theoretical background and crystallization of a concept of 'two-sided absorptive capacity' which aims to explicate the role of analytics skills while building absorptive capacity in data-driven environments.
\end{abstract}

Keywords Absorptive Capacity, Customer Knowledge, Predictive Analytics, Big Data, Case Study

\section{Introduction}

The debate over the role of customer integration for better understanding and responding to their needs penetrated major organizational processes and functions $[1,2]$. Companies strive to capture and benefit from customer knowledge [3-6]. However, customer knowledge is not easy to explicate in order to integrate it into firm's routines and practices. Specific challenges appear in case of limited physical proximity to customers, for example e-businesses. In this settings, customer knowledge is usually explicated through customer behavior which is granulated into data, the companies generate online. This type of data is referred in both business and data science as Big Data [7]. However, data- per se - does not offer any specific value for the company, unless effective knowledge discoveries techniques are applied [8].

In order to maximize the value of customer involvement, companies need to be able build absorptive capacity (ACAP) - an ability of companies to recognize the role of external ideas and to utilize them within a firm [9]. Zahra and George [10] extended the debate and reconceptualized the ACAP construct in the light of dynamic capabilities. Lichtenthaler and Lichtenthaler [11] claimed that knowledge utilization outside and inside firm boundaries are crucial and coined a new term - knowledge management capacity - as building upon a dynamic capability perspective. Absorptive capacity is predominantly analyzed as a mediator of innovative processes [12-14]. Customer knowledge integration and management was mostly viewed in the light of physical proximity $[15,16]$. In the era of dominant online presence, the possibilities of physical interaction are limited. However, companies generate a huge amount of Big Data that can ensure competitive advantages [17, 18]. Nonetheless, to support the processes of external knowledge integration in such settings, we need to find efficient tools which would technically support and tackle the complexity of this problem. In this search, we assume predictive analytics being a sufficient technological tool to manage knowledge discovery processes [19].

Dwelling upon ACAP concept implementation outside the innovation field, considering previous studies in an interdisciplinary field $[20,21]$, this study examines the nature of ACAP in data-driven environment, and especially in cases when companies lack physical proximity with customers, yet can integrate customer knowledge generated from behavioral data. When we talk about 'customer knowledge', we refer to an analytical knowledge retrieved from data using predictive analytics. Cohen and Levinthal [9] highlighted that absorptive capacity rests on the prior knowledge and experience. With this in mind, this paper explores the peculiarities of prior experience and knowledge 
for building ACAP for sustaining analytical customer knowledge integration. Given this research aim, we pose the following research question: what is the nature of ACAP in data-driven environments? This study responds to the research question by analyzing the concept of ACAP in real-life context, analyzing eight case studies, that deal with customer integration through predictive analytics to a different extend. This paper contributes to the absorptive capacity theory and knowledge management by setting first foundations in extending the frontiers of ACAP.

The structure of the paper is as follows: first, theoretical foundations are presented to give an overview of previous findings in the field of customer integration, absorptive capacity, as well as potential and role of predictive analytics in knowledge generating processes; second, the research design and case study description are introduced; third, key empirical findings are presented; fourth, the peculiarities of absorptive capacity in given settings are discussed, followed by conclusions and implications.

\section{Literature Review}

\subsection{Customer Knowledge}

Building upon the role of external knowledge, customer knowledge, depending on the company and industry peculiarities, might appear one of the key sources of competitive advantage. In the recent decades businesses drastically shifted towards customer orientation [22], granting customers a role of co-innovator [23], new product co-developer [24-26], new service development [27, 28] or value co-creator $[29,30]$. The fundamental premise, in this regard, underlies the significant innovative potential, located outside firm boundaries [31], where the customers carry the most innovative power as they possess a 'need information' [23]. However, in order to unveil this power, the knowledge from customers must transmit to a company.

Company-customer interaction processes are analyzed predominantly in the light of an open dialog [32], enabled by the peculiarities of B-to-B settings. In these settings, companies are searching for the most active customers who possess the greatest innovative power and are more likely to contribute to the company with their knowledge. These are known as lead users [33-35]. However, identification of lead users outside B-to-B settings is extremely challenging, and in some cases companies would benefit not from exceptional individual opinions but from overall customer input.

The role of customer and customer knowledge integration is particularly discussed in the area of e-businesses [36-38]. Yet, little research is done in the area of explication and integration of specific tacit insights, regarded by von Hippel [39] as 'sticky information'. Besides customers limitations in articulating and communicating their needs with the companies, there are cases when knowledge is embedded in customer behavior and conventional methods fail to explicate it.

The development of the Internet opens up new possibilities for customer integration on a more practical level. Internet offers possibilities of learning about and from customers by observing their online behavior [40]. Much is said about integration of customers through social media applications and development of virtual communities and other online platforms, including e-commerce [41-43]. Such a practice requires a sufficient IT support to deal with a constantly increasing data pool, generating Big Data [18]. Companies, operating in B-to-C setting with a high exposure to online environment and variety of activities, face the significant challenge of managing customer involvement. On the other side, they (can) generate a significant amount of customer behavioral data which possesses great potential for decision-making processes [18]. Learning to uncover hidden potential in data, using specific techniques, becomes an increasing task for the companies. The main challenge for business is caused by significant involvement of technological side, where they might have limited expertise, as well as lack of openness towards change.

\subsection{Predictive Analytics}

Technological development set completely different rules for competition in terms of sustaining competitive advantage. In this vein, Davenport and Harris [19] shed the light on competing on analytics on a critically new strategic level. What is so special and crucial about business analytics? First of all, it is bound to the exponentially increasing amount of data generated via different sources. Some companies ignore it as being impeded by data complexity and diversity; while other recognize the potential of data and search for the tools which would technically support data generation, assessment and analysis processes. These companies benefit in terms of dominant knowledge about their customer needs, market trends, operational costs and supply chain as the role of coherent data management techniques [19, 44, 45].

Complexity of Big Data in business is tackled by a variety of applications, where business analytics plays a crucial role as it has a potential to sustain firm's competitive advantage [46]. Business analytics is defined as "[...] an integration of disparate data sources from inside and outside the enterprise that are required to answer and act on forward-looking business questions tied to key business objectives" [47]. Business analytics differs with regard to the purposes it serves. Descriptive analytics, for example, is oriented to process historical data on the past events in a systematic way $[48,49]$. On the contrary, predictive analytics (PA) addresses predominantly the question "why certain events happened and what can we learn from it?". Siegel [50] defines predictive analytics as a "[...] technology that learns from experience (data) to predict the future behavior of individuals in order to drive better decisions".

The advantages of PA are usually argued on generalized to decision-making processes in all the corporate areas $[50,51]$. 
Scrutiny indicated that less - if anything - was said about utilization of PA for customer knowledge integration. PA enables uncovering hidden patterns in customer behavioral data to manage customer input and improve product and service provisions [52]. Important to note, that technology per se does not sustain competitive advantage but understanding of its application, e.g. to sustain information flows, ensures value maximization [53]. Given the technological complexity of the issue, companies have to learn to integrate customers, using innovative technologies of data mining.

\subsection{Absorptive Capacity}

The concept of external idea generation was coined by Cohen and Levinthal [9] who defined "[...] the ability of a firm to recognize the value of new, external information, assimilate it, and apply it to commercial ends" as absorptive capacity. However, not only recognition but exploitation of external information is crucial for a company. Zahra and George [10] reconceptualized the absorptive capacity and defined it as dynamic capabilities of a firm to create knowledge in order to enhance other organizational capabilities and distinguish between potential and realized absorptive capacities, which are dependent on the organizational antecedents [54]. In this vein, Lane et al. [55] distinguished between three forms of learning - exploratory, transformative and exploitative - as processes which constitute absorptive capacity. Building upon this debate, Lichtenthaler and Lichtenthaler [11] developed a unified knowledge management capacities framework where absorptive capacity stands for external knowledge exploration capabilities.

Absorptive capacity as an ability to integrate new information is dependent on the previous firm experience and knowledge [9]. However, not only these but also types of knowledge determine absorptive capacity [56]. The related study addressed this dependencies in the scope of international expansion, identifying areas of experience which influence ACAP and, respectively, foreign market knowledge [57]. Absorptive capacity is predominantly seen as a mediator of certain processes in the company, impact of external knowledge on innovation performance and firm performance [58, 59], impact of prior experience on utilization of external market knowledge [57], research activities and search for innovation [60, 61].

The limitations of absorptive capacity in the context of business intelligence were identified and challenged by Gonzalez and Muina [62]. In this vein, they coined the concept 'smart absorptive capacity' to highlight those peculiarities of absorptive capacity, given the technological environment. The explorative research-in-progress on big data analytics in the context of building absorptive capacity was offered by Liu [63] who asserts the positive impact of Big Data analytics on absorptive capacity, yet empirical observation and confirmation of hypotheses is to follow.
The moderating role of ACAP is enabling innovative processes by customer integration in the context of knowledge-intensive companies has been addressed by Ryzhkova and Pesämaa [64], indicating that knowledge of customer preferences contributes to firm innovativeness. In case of companies operating online and having limited possibilities of direct customer input, new approaches to manage customer knowledge are required [17]. Referring to postulates of Cohen and Levinthal [9] on the role of prior knowledge in building ACAP, we assume that this will apply not only to prior experience in customer involvement but also technology management. With this in mind, we take a further step into observing the nature of ACAP in data-driven environments.

\section{Methodology}

This research aims to explore the frontiers of absorptive capacity and learning from customers, overcoming the limitations of limited physical proximity to customers in online businesses. Although the concept of ACAP offers a comprehensive explanation of the knowledge generation processes, resting on the premises of prior knowledge and experience, in the given settings no research has been done. To address this research gap, we start by reviewing the previous research in the field; but as the comprehensive foundation for building a conceptual framework is missing, we quite early proceed to the empirical findings. Such a research design rests on abductive research approach, which gives us the opportunity to learn from the empirical scene and contrast the findings against the previous existing works in the realm of ACAP.

Preliminary observation indicated tentative assumptions on the existing limitation of absorptive capacity in the settings of technological development. In this vein, research design calls for interactive models to allow the flexibility of encountering contextual factors, influencing the research design through the whole study [65].

Given the novelty of the research settings, the research applies the principles of a qualitative study what offers the freedom of exploring the frontiers of the ACAP in the data-driven environments. Lack of possible interaction with customers to receive specific feedback or engage in direct interaction for improving the product or service, pushes towards exploitation of new ways of customer engagement. This problem description is oftentimes formulated at the business side, yet solutions here are difficult to find - what leads to limitations of customer integration and, respectively, managing customer knowledge. At the same time, the parallel development of data technologies offers the possibilities to crystallize valuable insights hidden in raw data, for example, on customer behavior etc. Building upon the research on the business problems and available technological solutions, this study takes a first step towards integrating these fields to address the peculiarities of 
integration of external customer knowledge through building ACAP.

Research on the customer integration and the processes of knowledge management is bound and influenced by the peculiarities of industry and business model settings. To cover contextual conditions where the learning from customers takes place, a case study was applied as a research strategy [66].

To identify the changing nature of ACAP, we have conducted five case studies (Table 1) to observe how these companies manage the integration of external customer knowledge in the scope of limited proximity to their customers. This study addresses ACAP as a complex and dynamic construct that is affected by the internal firm processes and logic of conducting business. Building upon the case studies evidence, the research aims to observe how companies position the role of customer in their company, as well as how they utilize potential of technological advances for overcoming limitations of direct customer communication. In this case we refer to customer integration using the means of data science. Since this is a first approach to address this research problem in such settings, we do not limit case selection by narrow industry, age or company type criteria. On the contrary, we studied companies from different sectors and different maturity level to get a broader picture on how companies manage customer knowledge using analytics technologies. This appears to be a limitation of the study but it will offer the first foundation to further in-depth research in more specific settings.

As the research process evolved, the study, which is related to the technology field, called for an integration of technology experts to ensure a more comprehensive and coherent conclusions and implications in a technological perspective. For that purpose, three case studies with a full technological perspective were included to eliminate biases of business perspectives on the researched issues and increase the quality of research [67]. Further, for ensuring research quality through increasing data input quality, both primary and secondary data was included into the cases development process [68]. Primary data was collected through conducting interviews with companies' managers, focusing on what is the role of customers for their companies, and how they utilize customer behavioral data. To ensure the integrity of the respondents, all the company names were anonymized.

Table 1. Case studies overview

\begin{tabular}{|c|c|c|c|c|}
\hline $\begin{array}{l}\text { Service } \\
\text { companies }\end{array}$ & Sector & $\begin{array}{l}\text { Business life } \\
\text { cycle stage }\end{array}$ & $\begin{array}{l}\text { Experience in } \\
\text { customer } \\
\text { integration }\end{array}$ & $\begin{array}{l}\text { Experience in } \\
\text { analytics }\end{array}$ \\
\hline Case study 1 & finance & mature & $\begin{array}{l}\text { shift towards } \\
\text { customer- } \\
\text { oriented } \\
\text { company }\end{array}$ & satisfactory \\
\hline Case study 2 & energy & mature & limited & limited \\
\hline Case study 3 & e-commerce & growth & $\begin{array}{l}\text { limited efforts } \\
\text { are done }\end{array}$ & limited \\
\hline Case study 4 & healthcare & start-up & $\begin{array}{l}\text { customer- } \\
\text { centered } \\
\text { company }\end{array}$ & $\begin{array}{l}\text { significantly } \\
\text { rely on } \\
\text { analytics }\end{array}$ \\
\hline Case study 5 & $\begin{array}{l}\text { public } \\
\text { sector }\end{array}$ & start-up & $\begin{array}{l}\text { significantly } \\
\text { rely on } \\
\text { customer } \\
\text { knowledge }\end{array}$ & $\begin{array}{l}\text { significantly } \\
\text { rely o } \\
\text { analytics }\end{array}$ \\
\hline
\end{tabular}




\section{Empirical Findings}

\subsection{Where Are Your Customers: Empirical Evidence from the Case Studies}

Despite the extensive debate in the literature and praxis on the role of customers and their importance for improving firm performance, differences in understanding and managing customer input was evident in the scope of this research. A customer-centric approach to managing business processes is especially typical for service companies [69]. Yet, even in such specific settings there tend to be a great deviation in understanding the value and role of customer knowledge.

Customer role differs across the industries and companies, resulting in proactive and reactive firm's attitude towards the integration of customer knowledge. Even though customer knowledge opens new possibilities for the companies to improve their performance, in many cases customer input remains 'optional' for majority of companies, especially mature. Established in the time of limited possibilities of managing customer involvement and knowledge on a broad scale, such companies have deeply established strategies and processes of running business for the customers, not with the customers. Important to emphasize that lack of customer involvement does not mean instantaneous company fail but it impedes improvements in company's performance. Such a conclusion appeared evident through the case studies 1,2 and 3 that successfully run the business without proactive customer involvement:

"[...] the main role of customer is that customer needs to know us, needs to be told that our product is great and buy it. That's the role of the customer" (Case 3).

Notable is that they realize the potential of gaining customer knowledge; however the required change to refine its business model and rearrange its processes hinders the steps towards customer integration. Davenport and Harris [19] have fairly noticed that companies do not compete on the products and services they offer anymore but on how efficiently they manage their business processes. Understanding of this principle was evident in all the case studies, yet some explicitly indicated that will not make any changes inside the company unless their business is getting worse and the change implementation is irrevocable:

"Everyone is aware of it [value of customer input] and knows that we should address it but at the moment nothing is pushing us. A lot of people, like our competitors, do not use it either and so, we are not very much pushed with that" (Case 2).

Analysis of the case studies of examined companies, coupled with the expert opinions of data analysts, indicated the tremendous role of organizational culture, and thus, business model that embraces all the business processes. Despite the understanding that customer input might be valuable for the company, not all are rushing to refine their business models to center the positioning of customers. Although companies are striving to improve their performance to maximize customer value, customer remains exceptionally at the receiving end of the value chain.

At first, it might be concluded that mature, especially brick-and-mortar companies, tend to indicate the least shift towards customer input integration. Companies from case studies 1 and 2 which operate at the market more than 20 years indicated limited focus on customer input. They claimed the recognition of a changing customer role. However, going through this change by themselves requires the implementation of significant change process - not everyone, including top management, is ready for that:

"Not a single leader in the company was eager to use the customer knowledge in such a way that it would impact our behaviour. I think we simply need more people in the company who are aware of the scope, process and benefits that customer knowledge brings to the company to be able to use it" (Case 2).

This observation might lead to the conclusion that these companies are less customer oriented due to their mature and well-established business models, determined by a long time at the market. However, this conclusion is challenged by the findings from case study 3 . The e-commerce company could be among those that should benefit the most from customer behavior. Such companies tend to generate knowledge on customer purchasing behavior which is a source of understanding customer needs and future market trends. Companies from this sector indicate high level of analytics adoption for managing data. Furthermore, company 3 is relatively new which leads to the conclusion on proactive customer integration, drawing upon the age and sector. However, the findings come at odd as this company indicated very limited customer integration, referring not only to the current actions but also general attitude. This company, however, indicated understanding of customer input for improving services and firm performance in general. To address it, some steps were undertaken in the company, however, it is led by the external market pressure (looking that other companies in the sector are doing it) rather than internal intrinsic motivation to improve firm performance by managing customer knowledge input:

"Suddenly our competitors are ahead of us... but it might be already too late" (Case 3).

Findings from this case, contrasted against the findings from cases 1 and 2, lead to the conclusion that it is not the age but organizational culture and initial positioning in business model what determines the role of customer for a company. This conclusion was also evident throughout all the case studies, including all the experts.

"I think it [need for making changes in a company towards customer integration] has changed a lot and it all 
started with new senior leadership which understood that and who pushed that down to the teams" (Case 1).

New ventures indicated different approach and attitude in managing customer knowledge, referring to cases 4 and 5 . These companies build customer-centric business models while implementing active customer integration. Initially these firms are looking for the ways to maximize customer value by implementing innovative ways of problem solving which could not be done using conventional methods. Thus, strong customer focus is not dependent on the initial business process organization, neither it is impeded by a firm age; the main reason is rooted in firm's intention, vision of the future and means to achieve business goals. These companies indicated completely different understanding of customer knowledge which is hidden in behavioral data:

"These guys having problems with customer engagement, so they want to engage more customers, they want to learn more from the customers" (Case 4).

To unfold this potential, they look for and apply technologies for addressing this challenge. All the processes in such companies are aligned with customer orientation and solving the problems in a way that was impossible to manage, using conventional methods and approaches. Thus, these companies place customer knowledge integration into the center of their business models.

\subsection{Role of Predictive Analytics in Managing Customer Knowledge Integration}

Peculiarity of current business processes are determined by increasing role of online activities. Even classical brick-and-mortar companies increase their online presence to meet the changing market trends. Interesting to ask about the intention of online presence: do they have to, because customers are there or do they want to because they recognized the potential offered by online-based processes? We cannot find a single answer, neither makes a generalization. The reasoning differs among the companies. Mature companies are rather pushed by the technological development. This was confirmed by the data experts as well.

Internet was predominantly used by the companies for rendering their services or as sales platform. However, in the recent times the new trend penetrated business environment. This was coined by the concepts of Big Data and analytics [70]. The overarching idea implies that any online activity it traceable, and if properly managed, offers the great possibilities to enhance decision-making and business process, to sustain competitive advantage.

The parallel development of data processing technologies has a great tendency of early penetration of areas where no other techniques can be applied. Technological development already offers very efficient tools and approaches for extracting information and learning from data.
"These companies, they need to be looking into these kind of things [data and analytics] because the time they have until the next tipping point of innovation and they miss it. If these companies don't look into the future when they are in a fast living environment, they are out of the business quicker than they can see" (Analytics expert 1).

This aspect leads to the tentative firm classification: those that initially develop their business model around solving certain business problem, heavily relying on data and analytics; and those with traditional approach that find data utilization and all the underlying processes as outlying. Analysis of companies' dominant logic regarding customer integration alongside with the attitude and efforts towards predictive analytics implementation revealed some interesting patterns and dependencies. Some companies (e.g. case studies 4 and 5) build the whole their business model around utilization of data which is great source of customer input, especially in cases when any physical interaction with customers is not possible. In many cases, customers have difficulties articulating what they want or need. However, there are cases where articulation of certain behavioral traits is hardly possible, yet they hold great valuable information. For medical institution, to draw conclusions about health condition of certain patients and make recommendation, it requires close interaction with those patients:

"You use the wearable so you can track your physical activity, you can see your heart rate but, as we see it and we believe in it, the wearable is not there to interact with it, the wearable is there to do things for you. It should assist you" (Case 4)

Thus, customer knowledge is becoming the core aspect in the business model and brings customer interaction and involvement to a new level. This type of knowledge, however, is extremely difficult to extract and assimilate, as it rooted in the subconscious behavior. For example, every person takes medications in a way determined by own life-style, occupation, temper etc. Moreover, they do not even follow or can verbally express when and how they take medications, what behavioral or external factors determine this process. This makes such information on customer behavior extremely 'sticky', as coined by von Hippel [39]. Peculiarity of such information calls for the techniques to extract this information, process it and make it ready for utilization. Analytics, as a tool for generating insights from the data which was difficult or impossible to extract earlier, strikes the potential of tackling information 'stickiness'.

Interestingly enough that new ventures that build their business models around analytics and data utilization, do not explicitly indicate information 'stickiness' and unveiling its value as the main motivation behind their businesses. Moreover, their definition of business goals and objectives is highly dependent and goes along with the alignment of analytics goals. It makes the analytics being integrated into business models and firm dominant logic, shaping the respective business processes with regard to business and 
analytics needs:

"It [predictive analytics utilization] is rather depending on the business culture of the company: how open are they to try new things, how open are they into going to cumulative risks" (Analytics expert 2).

In this vein, the customer integration through the utilization of behavioral data differs from mature companies. These companies tend to be bound to business objectives defined years ago with regard to the market needs and demands at that time. Besides the limited experience and competences in customer integration, mature companies are hindered by the lack of technology competences in regard with data analysis. The researched companies did not have previous experience of data utilization for any other purpose in the company, thus it was evident that this poses barriers towards building customer analytical knowledge. Dwelling on this, companies face difficulties seeing data analytics as a tool for managing customer integration. This logic applies to the other perspective as well: lack of proactive approach towards customer integration hinders probing the data techniques as a way to enhance customer knowledge management.

Differently looks the situation for the companies residing on the side of extensive data experience (cases 4 and 5). Peculiarity of these companies is that they understand the potential of data, alongside with principles of data mining, and shape of possible outcome. With this in mind, they look for business problems which would benefit more from the data utilization:

"We are working for something like prescriptive analytics for politicians. So, it's like predictive analytics but we also suggest what they want to do, based on the data we gather" (Case 5).

Companies with extensive experience in technological sphere stand out in their way of customer integration. In this case, predictive analytics not just improves customer input; it initially sets it at a different level where customer knowledge, generated by predictive analytics, is the main input for service rendering. Concluding upon the aspects of customer knowledge and the role of analytics in facilitating knowledge creation and assimilation, we could see the dependencies between managing customer knowledge effectively and analytics (technological) capabilities.

\section{Towards Building 'Two-sided Absorptive Capacity'}

It has been observed that learning from the customers and establishment of efficient processes of external knowledge generation and assimilation is connected to the firm experience in both spheres. This empirical finding conforms the ideas of Cohen and Levinthal [9] who state that absorptive capacity rests on the prior knowledge and experience. In case of building sufficient systems of managing customer knowledge, the ability to generate this knowledge is challenged by the peculiarities of its locus. This knowledge is tacit by nature, articulated through customer behavior only. This calls for techniques and tools to explicate this knowledge. We have already introduced predictive analytics as one of the technologies of extracting knowledge from behavioral customer data.

In most cases, customer integration is regarded in a conscious way. Customers are asked for an input through face-to-face interaction (mostly possible in B-to-B settings) or encouraged to share their experience through online applications, like social media etc. All this implies that customers should be motivated and interested in sharing their experience which is eventually difficult to generate, process and assimilate in a consistent manner. In this study, however, we refer to the businesses that have no possibilities of direct customer integration, and cannot benefit from any form of customer feedback due to the peculiarity of their business model. It calls for utilization of ways to gain customer knowledge without 'asking' customers for cooperation. Realizing that behavioral data is granulated customer knowledge, such companies have a possibility for passive, subconscious customer integration. Eventually, customers get customized offerings without any special effort, while companies increase customer satisfaction, thus customer retention and firm performance. This, however, is ensured only if both - attitude towards customer knowledge integration and analytics potential - are aligned and strategically utilized.

Referring to the theoretical foundations of absorptive capacity and the ability to manage external knowledge flows $[9,10,58]$, we can conclude that analytical customer knowledge integration, articulated in data, depends on the previous experience in customer integration. Although in this case we rather refer to passive customer integration, yet we observed that any experience in customer integration, regardless its type and strategies applied, has a positive impact on the ability to generate customer knowledge from behavioral data. We infer that absorptive capacity depends not only on prior experience and knowledge but also on the openness and desire to gain this knowledge. It is critical for the given problems settings that is characterized by significant barriers towards external knowledge integration, caused by the lack of customer proximity, difficulties to explicate knowledge from data and, at the first place, recognize the potential of such customer behavioral data. These all require certain dominant logic towards new strategies and approaches of external knowledge integration, which were not utilized earlier [71]. Such prerequisite towards building absorptive capacity is particularly difficult to achieve in mature companies with well-established dominant logic and perceptions of certain issues, like the role of customers. These companies are less likely to recognize the role of knowledge hidden in behavioral customer data, being hindered by a lack of experience coupled with low risk tolerance.

Absorptive capacity as a prerequisite for external 
customer knowledge generation from data utilizing predictive analytics, in every observed case, appeared to be dependent on the prior technological experience. Prior experience in business intelligence practices accelerates adoption of advanced analytics techniques. At this point it is important to emphasize, that only prior experience in analytics not any technological tool (e.g. Microsoft EXCEL) had positive impact on building absorptive capacity. In fact, companies that used Microsoft EXCEL for managing customer data were convinced that their approach is sufficient enough and were reluctant to recognition of potential of predictive analytics for knowledge discoveries.

Furthermore, prior experience in analytics had greater impact on building absorptive capacity than previous customer integration experience. Thus, companies with comprehensive competences in analytics demonstrate greater results in developing business models for maximizing their absorptive capacity.

In this vein, new ventures that rest on comprehensive analytics skills and competences bring the processes of external knowledge integration and building absorptive capacity to a new level. Instead of 'fitting' these processes into existing company structure and building absorptive capacity within these borders, these companies maximize the utilization of analytics specifically for addressing the problem, for instance, customer knowledge integration, thus increasing their absorptive capacity. However, regardless the comprehension level, the dependency of absorptive capacity on prior analytical experience was evident in all the cases.

Departing from the concept 'smart absorptive capacity' by Gonzalez and Muina [62], we identified that ability to learn from the external information, e.g. from customers, and generate analytic knowledge is also dependent on predictive analytics absorptive capacity. The very specific settings of online presence and learning from passive customer involvement, define the double impact on absorptive capacity: (I) to recognize and integrate knowledge from customer, while (II) resting on the ability to integrate and build advanced analytics competence. Building upon the role of prior knowledge and experience [9], we identified these would apply simultaneously to customer integration processes, as well as analytics experiences. In other words, none of these issues independently contribute to building absorptive capacity. This inference reshapes the nature of absorptive capacity towards crystallization of two dimensions of absorptive capacity, related to customer integration and analytics. Thus, we coin this notion as 'two-sided absorptive capacity' which is more applicable for analyzing external knowledge integration in data-intensive environments. The antecedents and dependencies of absorptive capacity are presented below (Figure 1).

The first findings, confirming the positive impact of customer relationship and technology capacities on firm performance were introduced by Tzokas et al. [20]. In case of data-driven environments, these findings are also evident; however, they indicated peculiar nature. Although, technological capability is critical, it cannot be separated from customer integration competences, as it loses its value if not aligned with the company business goals and dominant logic. The case of building absorptive capacity in data-driven customer knowledge integration indicated elevated interconnectedness and dependencies between different types of prior experiences and their derivation from firm dominant logic. Firm dominant logic was a reason for current state of customer integration and implementation of new ways of its enhancement.

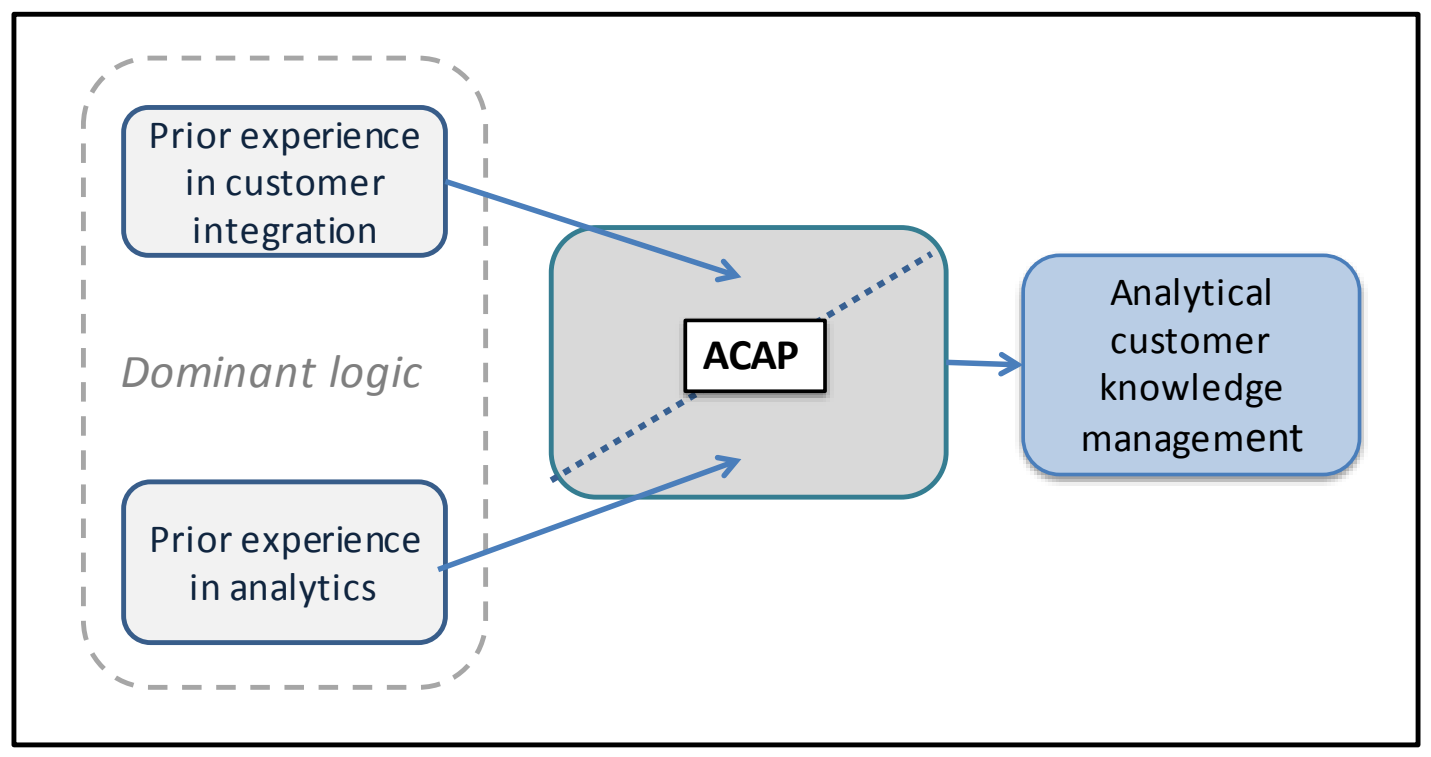

Figure 1. 'Two-sided absorptive capacity' 


\section{Conclusions}

This paper explores the concept of absorptive capacity developed by Cohen and Levinthal [9] in the data-driven environments. Dwelling on this peculiarity of absorptive capacity, new technological improvements are triggered by already existing practice in certain domain. Besides technological, there are other dimensions of these issues, namely experience in specific practices of customer involvement for driving external knowledge assimilation. Companies which are driven by the need of customer involvement and accumulated significant experience in this regard might be more active in recognizing value and adopting technological tools.

While analyzing eight case studies, we were able to observe striving peculiarities in building absorptive capacity. Build upon these, this study extends the concept of absorptive capacity in given settings and introduces the concept 'two-sided absorptive capacity'. This notion aims to address the generalization of absorptive capacity on prior knowledge and experience, by explicating the two areas where these are critical. Its importance is rooted in the need to highlight the significant role of analytics knowledge and competences in managing external knowledge and enhancing customer integration in a way that is limited by lack of direct interaction.

This study has a few limitations, though. The research is based on the eight case studies which limits the generalizability of the findings. Besides, since this study takes a first step towards observing the concepts of learning from customers and absorptive capacity in data-driven settings, the case study selection does not follow very specific criteria but rather embraces a wide spectrum of firm peculiarities in order to set the borders of the researched constructs. Further studies could be done by addressing specific industries, firm age (mature or new ventures) and business models innovation to embrace data potential and complexities, as well as the role of firm dominant logic for the purpose of enhancing external knowledge utilization.

This study offers both theoretical and empirical implications. As for the former, this research extends the concept of absorptive capacity, proving that in certain settings have a great impact on constructs and their dependencies in case of building absorptive capacities. As for latter, managers, while aiming to enhance integration of customer knowledge, are recommended to simultaneously address the technological (analytics) aspects. Building absorptive capacity to integrate customer knowledge rests on the understanding the role of analytics in retrieving customer knowledge from behavioral data. This calls for strategies that would tackle the interdependency of customer integration issues with the utilization of predictive analytics tools.

\section{REFERENCES}

[1] E. v. Hippel, Democratizing innovation, MIT Press, Cambridge, 2005.

[2] D. de Smet, A.-L. Mention, M. Torkkeli. Innovation-related knowledge from customers for new financial services: A conceptual framework, Journal of Innovation Management, Vol.1, No.2, 67-85, 2013.

[3] A. J. Campbell. Creating customer knowledge competence: managing customer relationship management programs strategically, Industrial Marketing Management, Vol.32, No.5, 375-383, 2003.

[4] J. Füller, M. Bartl, H. Ernst, H. Mühlbacher. Community based innovation: How to integrate members of virtual communities into new product development, Electron Commerce Res, Vol.6, No.1, 57-73, 2006.

[5] E. Enkel, O. Gassmann, H. Chesbrough. Open R\&D and open innovation: exploring the phenomenon, R\&D Management, Vol.39, No.4, 311-316, 2009.

[6] B. Edvardsson, P. Kristensson, P. Magnusson, E. Sundström. Customer integration within service development - A review of methods and an analysis of insitu and exsitu contributions, Technovation, Vol.32, No.7-8, 419-429, 2012.

[7] A. McAfee, E. Brynjolfsson, T. H. Davenport, D. J. and B. D. Patil. Big Data: The management revolution, Harvard Business Review, Vol.90, No.10, 61-67, 2012.

[8] S. LaValle, E. Lesser, R. Shockley, M. S. Hopkins, N. Kruschwitz. Big data, analytics and the path from insights to value, MIT Sloan Management Review, Vol.52, No.1, 21-32, 2011.

[9] W. M. Cohen, D. A. Levinthal. Absorptive capacity: A new perspective on learning and innovation, Administrative Science Quarterly, Vol.35, No.1, 128-152, 1990.

[10] S. A. Zahra, G. George. Absorptive capacity: A review, reconceptualization, and extension, Academy of Management Review, Vol.27, No.2, 185-203, 2002.

[11] U. Lichtenthaler, E. Lichtenthaler. A capability-based framework for open innovation: Complementing absorptive capacity, Journal of Management Studies, Vol.46, No.8, 1315-1338, 2009.

[12] W. Tsai. Knowledge transfer in intraorganizational networks: Effects of network position and absorptive capacity on business unit innovation and performance, Academy of Management Journal, Vol.44, No.5, 996-1004, 2001.

[13] M. Nieto, P. Quevedo. Absorptive capacity, technological opportunity, knowledge spillovers, and innovative effort, Technovation, Vol. 25, No. 10, 1141-1157, 2005.

[14] K. Kostopoulos, A. Papalexandris, M. Papachroni, G. Ioannou. Absorptive capacity, innovation, and financial performance, Journal of Business Research, Vol.64, No.12, 1335-1343, 2011.

[15] M. Garcia-Murillo, H. Annabi. Customer knowledge management, The Journal of the Operational Research Society, Vol.53, No.8, 875-884, 2002.

[16] A. Bueren, R. Schierholz, L. Kolbe, W. Brenner. Customer knowledge management: Improving performance of customer 
relationship management with knowledge management, The $37^{\text {th }}$ Annual Hawaii International Conference on IEEE, 2004.

[17] P. Gamble, M. Chalder, M. Stone. Customer knowledge management in the travel industry, Journal of Vacation Marketing, Vol.7, No.1, 83-91, 2001.

[18] P. Bell. Creating competitive advantage using Big Data, Ivey Business Journal, Vol. May/June, 1-5, 2013.

[19] T. H. Davenport and J. G. Harris, Competing on analytics: The new science of winning, Harvard Business School Press, Boston, 2007.

[20] N. Tzokas, Y. A. Kim, H. Akbar, H. Al-Dajani. Absorptive capacity and performance: The role of customer relationship and technological capabilities in high-tech SMEs, Industrial Marketing Management, Vol.47, 134-142, 2015.

[21] N. Kabir, E. Carayannis. Dig Data, tacit knowledge and organizational competitiveness, Journal of Intelligence Studies in Business, Vol.3, 54-62, 2013.

[22] S. L. Vargo, R. F. Lusch. Evolving to a new dominant logic for marketing, Journal of Marketing Management, Vol.68, 1-17, 2004.

[23] S. Thomke, E. von Hippel. Customers as innovators: A new way to create value, Harvard Business Review, Vol.80, No.4, 74-81, 2002.

[24] M. A. Kaulio. Customer, consumer and user involvement in product development: A framework and a review of selected methods, Total Quality Management, Vol.9, No.1, 141-149, 2010 .

[25] S. Lagrosen. Customer involvement in new product development, European Journal of Innovation Management, Vol.8, No.4, 424-436, 2005.

[26] S. L. Brown, K. M. Eisenhardt. Product development: Past research, present findings, and future directions, Academy of Management Review, Vol.20, No.2, 343-378, 1995.

[27] P. Carbonell, A. I. Rodríguez-Escudero, D. Pujari. Customer involvement in new service development: An examination of antecedents and outcomes, Journal of Product Innovation Management, Vol.26, No.5, 536-550, 2009.

[28] I. Alam. An exploratory investigation of user involvement in new service development, Journal of the Academy of Marketing Science, Vol.30, No.3, 250-261, 2002.

[29] C. K. Prahalad, V. Ramaswamy. Co-creating unique value with customers, Strategy \& Leadership, Vol.32, No.3, 4-9, 2004.

[30] V. Ramaswamy. Co-creation of value-towards an expanded paradigm of value creation, Marketing Review St. Gallen, Vol.26, No.6, 11-17, 2009.

[31] H. W. Chesbrough. The era of open innovation, Managing Innovation and Change, Vol.127, No.3, 34-41, 2006.

[32] L. Aarikka-Stenroos, E. Jaakkola. Value co-creation in knowledge intensive business services: A dyadic perspective on the joint problem solving process, Industrial Marketing Management, Vol.41, No.1, 15-26, 2012.

[33] E. von Hippel. Lead users: a source of novel product concepts, Management of Science, Vol.32, No.7, 791-805, 1986.
[34] E. Olson, G. Bakke. Implementing the lead user method in a high technology firm: a longitudial study of intentions versus actions, Journal of Product Innovation Management, Vol.18, No.2, 388-395, 2001.

[35] P. Morrison, J. Roberts, D. Midgle. The nature of lead users and measurement of leading edge status, Research Policy, Vol.33, No.2, 336-351, 2004.

[36] J. E. Rowley. Reflections on customer knowledge management in e-business, Qualitative Market Research: An International Journal, Vol.5, No.4, 268-280, 2002.

[37] M. Plessis, J. Boon. Knowledge management in eBusiness and customer relationship management: South African case study findings, International Journal of Information Management, Vol.24, No.1, 73-86, 2004.

[38] C. Lopez-Nicolas, F. J. Molina-Castillo. Customer Knowledge Management and E-commerce: The role of customer perceived risk, International Journal of Information Management, Vol.28, No.2, 102-113, 2008.

[39] E. von Hippel. "Sticky information" and the locus of problem solving: Implications for innovation, Management Science, Vol.40, No.4, 429-439, 1994.

[40] A. L. Montgomery, K. Srinivasan. Learning about customers without asking, in the power of one-leverage value from personalization technologies, N. Pal and A. Rangawamy, Eds, Penn State University: eBRC Press, 2003.

[41] M. Sawhney, G. Verona, E. Prandelli. Collaborating to create: The Internet as a platform for customer engagement in product innovation, Journal of Interactive Marketing, Vol.19, No.4, 4-17, 2005.

[42] J. Füller, K. Matzler. Virtual product experience and customer participation-A chance for customer-centred, really new products, Technovation, Vol.27, No.6-7, 378-387, 2007.

[43] S.-C. Wu, W. Fang. The effect of consumer-to-consumer interactions on idea generation in virtual brand community relationships, Technovation, Vol.30, No.11-12, 570-581, 2010 .

[44] P. Trkman, K. McCormack, M. P. V. de Oliveira, M. B. Ladeira. The impact of business analytics on supply chain performance, Decision Support Systems, Vol.49, No.3, 318-327, 2010.

[45] M. A. Waller, S. E. Fawcett. Data science, predictive analytics, and big data: A revolution that will transform supply chain design and management, Journal of Business Logistics, Vol.34, No.2, 77-84, 2013.

[46] R. Sharma, P. Reynolds, R. Scheepers, P. B. Seddon, G. Shanks. Business analytics and competitive advantage: A review and a research agenda, in Bridging the Socio-technical Gap in Decision Support Systems, IOS Press, 187-198, 2010.

[47] J. P. Isson, J. Harriott. Win with advanced business analytics: Creating business value from your data, John Wiley \& Sons, New Jersey, 2013.

[48] S. LaValle, M. S. Hopkins, E. Lesser, R. Shockley, N. Kruschwitz. Analytics: The new path to value, MIT Sloan Management Review, Fall, 2010.

[49] T. H. Davenport. Competing on analytics, Harvard Business 
Review, Vol. January, 1-10, 2006.

[50] E. Siegel. Predictive analytics: The power to predict who will click, buy, lie, or die, Wiley, New Jersey, 2013.

[51] V. R. Srinivasan. Predictive business analytics, The Management Accountant, Vol.47, No.2, 211-215, 2012.

[52] J. F. Hair. Knowledge creation in marketing: the role of predictive analytics, European Business Review, Vol.19, No.4, 303-315, 2007.

[53] G. D. Bhatt. Knowledge management in organizations: examining the interaction between technologies, techniques, and people, Journal of Knowledge Management, Vol.5, No.1, 68-75, 2001.

[54] J. Jansen, F. A. van den Bosch, H. Volberda. Managing potential and realized absorptive capacity: How do organizational antecedents matter? The Academy of Management Journal, Vol.48, No.6, 999-1015, 2005.

[55] B. J. Lane, B. R. Koka, S. Pathak. The reification of absorptive capacity: A critical review and rejuvenation of the construct, Academy of Management Review, Vol.31, No.4, 833-863, 2006.

[56] T. Schmidt. What determines absorptive capacity, DRUID Summer Conference, 2005.

[57] K. Eriksson, S. Chetty. The effect of experience and absorptive capacity on foreign market knowledge, International Business Review, Vol.12, No.6, 673-695, 2003.

[58] A. Escribano, A. Fosfuri, J. A. Tribó. Managing external knowledge flows: The moderating role of absorptive capacity, Research Policy, Vol.38, No.1, 96-105, 2009.

[59] A. Fosfuri, J. Tribo. Exploring the antecedents of potential absorptive capacity and its impact on innovation performance, Omega, Vol.36, No.2, 173-187, 2008.

[60] K. R. Fabrizio. Absorptive capacity and the search for innovation, Research Policy, Vol.38, No.2, 255-267, 2009.
[61] V. J. García-Morales, A. Ruiz-Moreno, F. J. Llorens-Montes. Effects of technology absorptive capacity and technology proactivity on organizational learning, innovation and performance: An empirical examination, Technology Analysis \& Strategic Management, Vol.19, No.4, 527-558, 2007.

[62] P. M. González, F. E. G. Muiña. Absorptive capacity and smart companies, IC, Vol.10, No.5, 2014.

[63] Y. Liu. The effects of Big Data analytics and innovation culture on absorptive capacity and innovation, Online available from

http://epic.is.cityu.edu.hk/sigbps/BPS15/docs/SIGBPS2015 paper_15.pdf.

[64] N. Ryzhkova, O. Pesämaa. Absorptive capacity, collaboration with customers and innovation performance of gazelle companies in knowledge-intensive industries, International Journal of Innovation Management, Vol.19, No.5, 1550059 (27p.), 2015.

[65] J. A. Maxwell. Qualitative research design: An interactive approach, 2nd ed. Thousand Sage Publications, Oaks, 2005.

[66] R. K. Yin. Case study research: Design and methods, 4th ed., Sage Publications, Los Angeles, California, 2009.

[67] A. Bryman, E. Bell. Business research methods, 2nd ed., Oxford University Press, Oxford, 2007.

[68] N. Denzin. The research art: A theoretical introduction to sociological methods, Aldine, Chicago, 1970.

[69] K. E. Reynolds, S. E. Beatty. Customer benefits and company consequences of customer-salesperson relationships in retailing, Journal of Retailing, Vol.75, No.1, 11-32, 1999.

[70] H. Chen, R. H. L. Chiang, V. C. Storey. Business intelligence and analytics: From Big Data to Big Impact," MIS Quarterly, Vol.36, No.4, 1165-1188, 2012.

[71] C. K. Prahalad, R. Bettis. The dominant logic: a new linkage between diversity and performance, Strategic Management Journal, Vol.7, 485-501, 1986. 